\title{
Effect of Textile Waste on the Mechanical Properties of Polymer Concrete
}

\author{
João Marciano Laredo dos Reis* \\ Mechanical Engineering Post-Graduate Program - PGMEC, \\ Laboratory of Theoretical and Applied Mechanics - LMTA, \\ Universidade Federal Fluminense - UFF, \\ Rua Passo da Pátria, 156, Sala 216, Bloco E, Niterói - RJ, Brazil
}

Received: June 7, 2008; Revised: December 15, 2008

\begin{abstract}
The mechanical behavior of polymer concrete reinforced with textile trimming waste was investigated. Two series of polymer concrete formulations were studied, with different resin/sand (i.e. binder/fine aggregate) weight ratios. In each series, recycled textile chopped fibers at 1 and $2 \%$ of the total weight was used. Flexural and compressive tests were performed at room temperature and load vs. displacement curves were plotted up to failure. In the study, both the influence of fiber content and resin/sand weight ratio were considered relative to the behavior of polymer concrete reinforced with textile fibers. A decrease in properties was observed as function of textile fibers content. When specific properties were considered, this tendency was kept. However, higher textile fibers content lead to a smoother failure, unlike brittleness failure behavior of unreinforced polymer concrete.
\end{abstract}

Keywords: recycling, textile fibers, polymer concrete

\section{Introduction}

The disposal of solid wastes is a major problem throughout the world. Recycling and use of these waste materials, is increasing worldwide, especially in constructions. Using recycled materials and wastes in constructions is becoming more popular due to shortages of natural mineral resources and increasing waste disposal costs. However, with increasing use of wastes in engineering applications, a need for further understanding of their engineering behavior is required.

Synthetic fibers were developed mainly to supply the high demand for textile products. Rayon and Nylon were the first ones to be developed and commercialized. Nowadays, textile fibers are manufactured from a unique type of fiber or from a combination of several fibers, natural or synthetic, providing a huge variety of final products ${ }^{1}$. Brazil is an important manufacturer of textile products worldwide according to previous studies ${ }^{2}$. The textile cuttings waste form those industries are usually disposed of as waste product which become an environmental nuisance because of its non-biodegradability, or burned in heaps thus releasing highly toxic fumes in the surrounding air.

The practice of disposal requires constant creation of new landfill spaces, which is in contradiction to the environmental goals, including ecosystem protection. Significant effort has been devoted to the reduction, reuse, and recycling of the waste materials. Typically, recycling technologies are divided into primary, secondary, tertiary, and quaternary approaches. Primary approaches involve recycling a product into its original form. Secondary recycling involves processing a used product into a new type of product that has a different level of physical and/or chemical properties. Tertiary recycling involves processes, such as pyrolysis and hydrolysis, which convert the waste into basic chemicals or fuels. Quaternary recycling refers to waste-toenergy conversion through incineration. All four approaches exist for textile, plastic, and paper recycling. Studies have indicated that many forms of fibers recovered from various waste streams are suitable for concrete reinforcement. The advantages of using such recycled fibers include generally lower cost to process than virgin fibers, and the elimination of the need for waste disposal in landfills.
Previous studies made in the most important manufacturing of textile products in Rio de Janeiro, Nova Friburgo, estimate proximally 40 ton/month of textile trimming waste from the lingerie industry. Previous researches done by the author show that polymer concrete can be reinforced with several types of fibers, both synthetic ${ }^{3,4}$ and natural ${ }^{5}$, and that textile waste cuttings when mixed with thermosetting polymer as binder produces a unique kind of composite material that can be used for low-cost lightweight construction ${ }^{6}$.

Polymer Concrete (PC) is a composite material in which polymeric materials, i.e. thermoset resins, are used to bond the aggregates, in a similar way to that of Portland cement concrete. $\mathrm{PC}$ rapidly proved to be an excellent repair for concrete. Thin overlays were produced which has the advantage of providing lightweight, fast curing and durable. Today, PC is used very efficiently in precast components for bridge panels, buildings, machine bases, and transportation components ${ }^{7,8}$. Improved mechanical strength and chemical resistance are basic advantages of PC in comparison to ordinary Portland cement concrete. Although three to five times stronger than conventional concrete, PC does display brittle characteristics that have limited its usefulness for load-bearing applications ${ }^{9}$.

\section{Research Significance}

A significant amount of fibrous waste from the textile industry and post-consumer product is disposed worldwide. This is not only a cause for environmental concern, but also represents a waste of useful resources. This paper contributes to the understanding of the characteristics of polymer concrete made with recycled textile fibers from clothing industry. It also demonstrates that waste materials leads to a more reliable structures at very low cost. It is expected that this research will stimulate further full-scale studies on waste fiber reinforcement and promote the use of such material in construction.

These textiles are generally those that most effectively translate yarns into stiff, strong composites. The textile cuttings are usually disposed of as waste product that become an environmental nuisance 
because of its non-biodegradability, or burned in heaps thus releasing highly toxic fumes in the surrounding air. Due to the influx of these voluminous wastes in our environment, turning them into useful materials serves a dual function: elimination of wastes, and introduction of a new product. This study explores the technical properties of a new product produced from textile waste cuttings in order to determine its usefulness as a new building material.

\section{Materials}

In the study, the textile waste cuttings are taken from the higher manufacturer of lingerie in Brazil, the industrial center of Nova Friburgo in Rio de Janeiro. The textile consists of cotton, polyester, silk and rayon. A homogenous single type of textile usually consists of a combination of these materials in various percentages. In the textile polymer composite material under study, foundry sand are mixed with thermosetting resin, epoxy, which is used as binder. The textile cuttings may not be conceived as either an aggregate or reinforcement. It does however contribute to the increase in volume of the mixture (which is the major function of an aggregate) less the weight, and intent to contribute to the increase in the flexural and compressive resistance (which is the major function of the reinforcement) due to its fibrous nature. Textile fibers reinforced polymer concrete were prepared in the same way as plain polymer concrete, with the incorporation of 1 and $2 \%$ in weight of chopped textile fibers. Those percentages were chosen according to previous studies on fiber reinforced polymer concrete ${ }^{3,4,5}$. The textile waste cuttings are trimmed into average lengths between 2 and $6 \mathrm{~cm}$.

The aggregate was foundry sand, which consists in quartz sand, designed by $40 / 50$, from JUNDU ${ }^{\circledR}$ used in the foundry industry, with a uniform granulometry. The epoxy resin system used was RR515 from SILAEX ${ }^{\circledast}$ based on a diglycidyl ether bisphenol A and an aliphatic amine hardener, it processed with a maximum mix ratio to hardener of 2:1 with low viscosity (500-700 MPa.s), which cluster the sand, giving high strength and cohesion. PC formulations were prepared by mixing foundry sand with the thermosetting resins.

Two series of PC formulations were studied, where different resin/ sand weight ratio value were used. The resin content varied from 10 to $12 \%$ by weight. Mix proportions are presented in Table 1 .

The specimens were specified with the code presented in Table 1 followed by letters $\mathrm{F}$, for flexural tests, and $\mathrm{C}$ for compressive tests. With those mix proportions, polymer concrete specimens were cast to prismatic $\left(40 \times 40 \times 160 \mathrm{~mm}^{3}\right)$ and cylinder $(\phi 50 \times 100 \mathrm{~mm})$ specimens, as illustrated in Figure 1, according to RILEM CPT PC-2 ${ }^{10}$ standard. For each formulation five cylinder specimens were cast. All specimens were allowed to cure for 7 days at room temperature.

Table 1. Mix proportion of PC formulations.

\begin{tabular}{ccc}
\hline Test series & $\begin{array}{c}\text { Resin: sand } \\
\left(\mathrm{w} . \mathrm{w}^{-1}\right)\end{array}$ & $\begin{array}{c}\text { Fiber content } \\
(\%)\end{array}$ \\
\hline Flexural & & 0 \\
EPO100F & $10: 90$ & 1 \\
EPO101F & $10: 90$ & 2 \\
EPO102F & $10: 90$ & \\
Compressive & & 0 \\
EPO120C & $12: 88$ & 1 \\
EPO121C & $12: 88$ & 2 \\
EPO122C & $12: 88$ & \\
\hline
\end{tabular}

\section{Flexural and Compressive Toughness}

Measurements of textile fibers reinforced polymer concrete under different loading conditions were performed in flexural and compression. Prismatic polymer concrete beams were tested in three-point bending up to failure at the loading rate of $1 \mathrm{~mm} / \mathrm{min}$, with the span of length of $100 \mathrm{~mm}$, according to RILEM CPT PCM- $8^{11}$ standard test method. The specifications of this standard, in terms of specimen geometry and span length, are similar to those specified in ASTM C348-02, standard test method for flexural strength of hydraulic cement mortars ${ }^{12}$. In both mentioned standards, shear effect is not taken into account on calculation procedure of flexural strength. Despite the very short span compared to the thickness, shear effect is disregarded. Polymer concrete is considered an isotropic material and the theory of plane cross-section is used. Flexural strength, considered as the strength under normal stress, was determined applying the following equation:

$$
\sigma_{f}=\frac{3 P l}{2 b h^{2}}
$$

where $\sigma_{\mathrm{f}}$ is the flexural strength; $\mathrm{P}$ is the maximum load recorded, 1 is the span length; $b$ and $h$ are respectively, the width and height of the prismatic specimens.

Cylinder polymer concrete specimens were tested in compression at the loading rate of $1.25 \mathrm{~mm} / \mathrm{min}$ according to ASTM C39-05 standard ${ }^{13}$.

Compressive strength were calculated according the following Equation:

$$
\sigma_{c}=\frac{F}{A}
$$

where $\sigma_{\mathrm{c}}$ is the compressive strength; $\mathrm{P}$ is the maximum load recorded; and $\mathrm{A}$ is the cross-sectional area of cylinder specimens.

Both flexural and compressive test set-up, are presented in Figure 2.

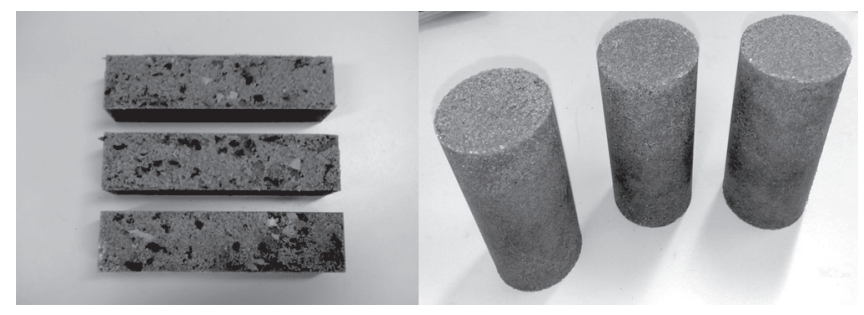

Figure 1. Examples of flexural and compressive specimens.

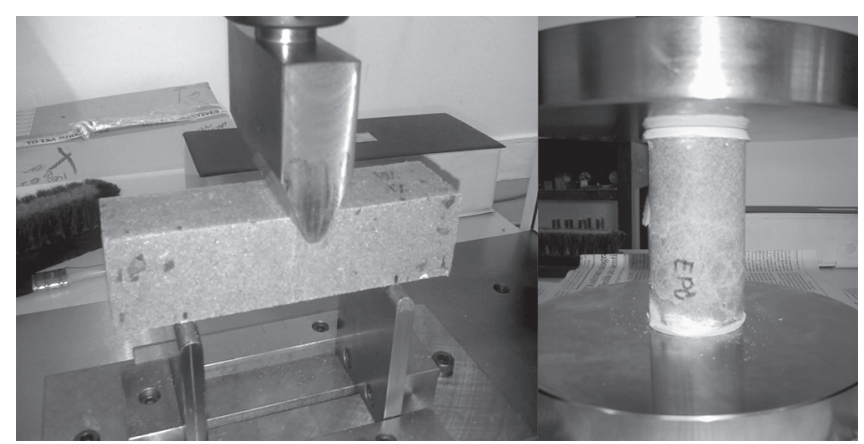

Figure 2. Flexural and compressive test set-up. 


\section{Test Results and Discussion}

Mechanical properties obtained from flexural and compressive tests conducted at Universidade Federal Fluminense (UFF) and Instituto Politécnico do Rio de Janeiro (IPRJ) are presented in the following tables. Table 2 displays the flexural tests results of all mixture formulations of polymer concrete.

The results displayed in Table 2 show that flexural strength of polymer concrete made with textile fibers decrease with the increase of textile fibers content. In average, flexural strengths decrease $27.4 \%$ for $1 \%$ textile fiber content and 50.7 for $2 \%$ textile fiber content, when compared plain $10 \%$ resin content polymer concrete.

A lower decrease of flexural strength is observed when plain $12 \%$ resin content polymer concrete are compared to 1 and $2 \%$ textile fiber reinforced polymer concrete. For $1 \%$ of fiber content a decrease of $18.5 \%$ is observed and for $2 \%$ of textile fiber content a decrease of $43.6 \%$ is calculated.

Comparing plain polymer concrete, $12 \%$ resin content plain polymer concrete is almost $25 \%$ strong, in flexion, than $10 \%$ resin content plain polymer concrete. In fact, even $12 \%$ resin content polymer concrete made with $1 \%$ of textile fiber content has a high flexural strength than plain $10 \%$ polymer concrete.

Figure 3 displays flexural strength vs. deflection curves from 3 -point bending tests performed on textile fiber reinforced and unreinforced polymer concrete. In bending, failure becomes less brittle as textile fibers content is increased in the polymer concrete mixture.

Ultimate failure load decrease is observed in all cases and failure becomes even less brittle, especially for $12 \%$ resin content polymer concrete reinforced with $2 \%$ of textile fibers. The unreinforced specimens collapse catastrophically and textile reinforced has a more soft failure, avoiding specimens from break completely, failure occurred but specimens did not break apart.

Increasing resin content increases the flexural strength in both formulations, unreinforced and textile fiber reinforced polymer concrete. This behavior was expected according to previous studies ${ }^{14,15}$.

In order to better understand the influence of resin and fiber content, a comparison chart of flexural properties are plotted in Figure 4.

From Figure 4, it is clear that increasing resin and fiber content higher flexural strength is obtained. Comparing flexural results from

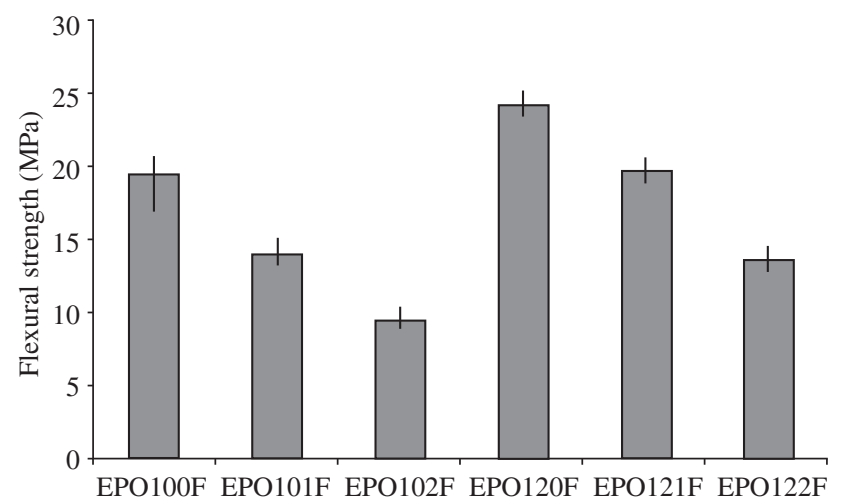

Figure 4. Flexural strength comparison of all polymer concrete formulations.

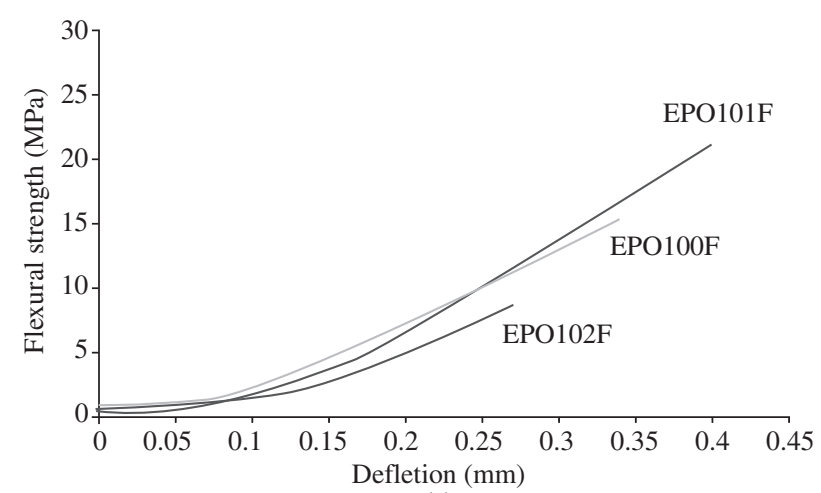

(a)

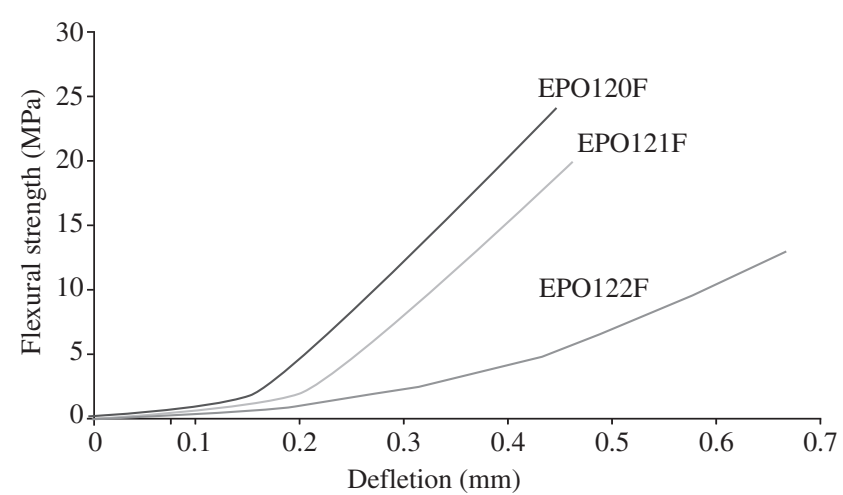

(b)

Figure 3. Some representative flexural strength vs. deflection curves of textile polymer concrete specimens.

Table 2. Flexural strength test results of textile polymer concrete (MPa).

\begin{tabular}{|c|c|c|c|c|c|c|}
\hline Specimen & EPO100F & EPO101F & EPO102F & EPO120F & EPO121F & EPO122F \\
\hline 1 & 20.59 & 13.24 & 10.07 & 24.70 & 19.46 & 13.54 \\
\hline 2 & 19.76 & 15.16 & 9.25 & 23.46 & 19.64 & 14.62 \\
\hline 3 & 19.14 & 13.56 & 10.47 & 25.28 & 20.69 & 12.88 \\
\hline 4 & 20.75 & 14.93 & 9.12 & 24.21 & 20.35 & 13.85 \\
\hline 5 & 16.90 & 13.64 & 8.98 & 23.72 & 18.81 & 13.53 \\
\hline Average & 19.43 & 14.11 & 9.58 & 24.27 & 19.79 & 13.68 \\
\hline St. Dev. & 1.56 & 0.87 & 0.65 & 0.74 & 0.74 & 0.63 \\
\hline $\mathrm{COV}$ & 8.01 & 6.20 & 6.83 & 3.03 & 3.76 & 4.61 \\
\hline CI $(95 \%)$ & 1.63 & 0.92 & 0.69 & 0.77 & 0.78 & 0.66 \\
\hline
\end{tabular}


textile fiber reinforced polymer concrete to textile reinforced cement concrete; specimens of polymer concrete have lower strength than ordinary cement. Previous researches ${ }^{6,16}$ show a reduce of $43 \%$ in flexural strength but generally $10 \%$ is observed on textile reinforced cement concrete when compared to plain ordinary cement concrete.

Like 3 pt bending tests showed, compressive tests show that the addition of textile fibers decreases the compressive strength of polymer concrete. Table 3 presents compressive strength comparison of all formulations tested plain and textile reinforced polymer concrete.

Analyzing the results of $10 \%$ resin content, polymer concrete becomes weak in compression as textile fibers were added. Textile fiber reinforced polymer concrete compressive strength decreases 30.3 and $43.1 \%$ for 1 and $2 \%$ of textile fiber content respectively, when compared to plain unreinforced polymer concrete.

The decrease, in terms of compressive strength, is even higher when resin content increase from 10 to $12 \%$ and fiber content was maintained. Comparing $12 \%$ resin content plain polymer concrete to $1 \%$ of textile fiber reinforced polymer concrete the compressive strength decreases $41.8 \%$ and its strength decreases more, $47.7 \%$, when $2 \%$ of textile fiber is added to the mixture.

Figure 5 plots some representative compressive strength vs. deflection curves from compressive tests performed on all formulations of textile fiber reinforced and unreinforced polymer concrete. Textile fibers reinforcement characteristics are observed during the compressive test. Increasing fiber content failure become less brittle in both cases of resin content. Unreinforced polymer concrete specimens failed in a brittle manner and shattered into pieces as the load dropped instantly to zero. In contrast, all textile fiber reinforced samples after reaching the peak load could still remain as an integral piece, with fibers holding the polymer matrix tightly together.

The compressive strengths for various mixes are compared in Figure 6.

Observing Figure 6, for 2\% textile fiber reinforced specimens, compressive strengths were lower than unreinforced polymer concrete in both resin content formulation. The reduce of strength for $12 \%$ resin content samples were higher than the strength decrease observed for $10 \%$ resin content specimens, indicating that textile fibers cause a strength reduction. When compared to textile reinforced ordinary cement concrete $^{6,16}$, polymer concrete specimens strengths were more affected by textile fibers. A reduce of $34^{6}$ and $22 \%$ in compression was observed in ordinary cement concrete.

\section{Conclusions}

The textile cutting waste, when mixed with thermosetting, epoxy resin and foundry sand produce a unique composite material the can be used for lightweight construction. The composite material produced exhibits lower flexural and compressive characteristics when reinforced with textile cutting wastes, i.e. textile fibers when added to polymer concrete mixture does not accomplish the expected reinforce or at least has the same strength characteristics of unreinforced polymer concrete.

Previous studies performed by the author with synthetic ${ }^{3,4}$ and natural ${ }^{5}$ fibers opened a good possibility of using textile fibers as polymer concrete reinforcement.

Other researches used textile fibers, as reinforcement in ordinary Portland concrete and the results were satisfactory, showing reduces of strength but not as higher as it happened in polymer concrete.

Textile fibers do not increase polymer concrete flexural and compressive strength but their addition to the mixture eliminates the

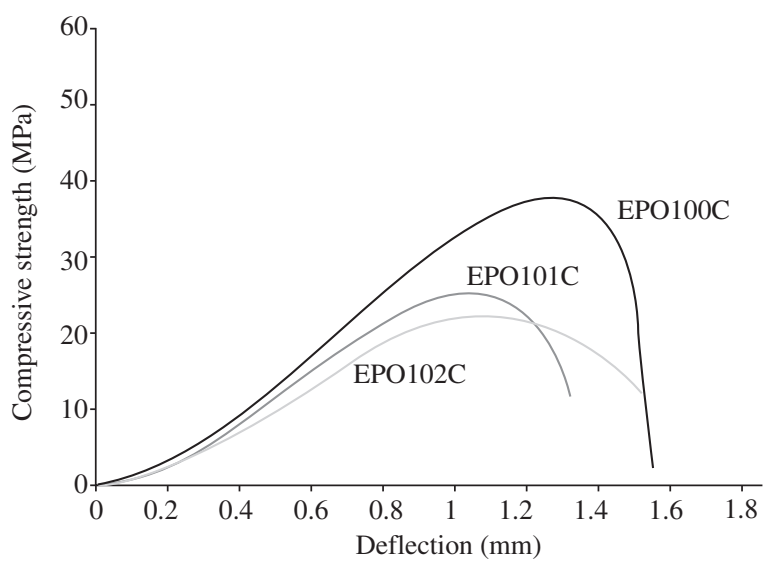

(a)

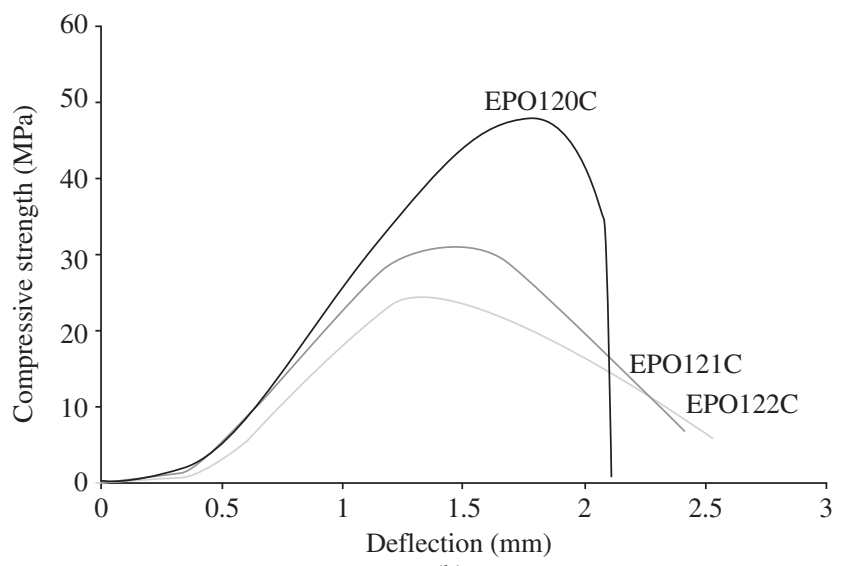

(b)

Figure 5. Some representative compressive strength vs. deflection curves of textile polymer concrete specimens.

Table 3. Compressive strength test results of textile polymer concrete (MPa).

\begin{tabular}{|c|c|c|c|c|c|c|}
\hline Specimen & EPO100C & EPO101C & EPO102C & EPO120C & EPO121C & EPO122C \\
\hline 1 & 34.35 & 22.37 & 19.45 & 36.45 & 30.07 & 24.19 \\
\hline 2 & 33.07 & 22.04 & 18.93 & 51.93 & 30.83 & 24.43 \\
\hline 3 & 27.60 & 20.43 & 18.09 & 44.09 & 24.09 & 22.58 \\
\hline 4 & 37.72 & 23.16 & 16.07 & 51.07 & 18.85 & 27.15 \\
\hline 5 & 25.78 & 22.42 & 17.65 & 47.65 & 30.78 & 22.84 \\
\hline Average & 31.70 & 22.08 & 18.04 & 46.24 & 26.92 & 24.24 \\
\hline St. Dev. & 4.92 & 1.01 & 1.31 & 6.29 & 5.32 & 1.82 \\
\hline $\mathrm{COV}$ & 15.53 & 4.58 & 7.24 & 13.60 & 19.76 & 7.50 \\
\hline CI $(95 \%)$ & 5.17 & 1.06 & 1.37 & 6.60 & 5.58 & 1.91 \\
\hline
\end{tabular}




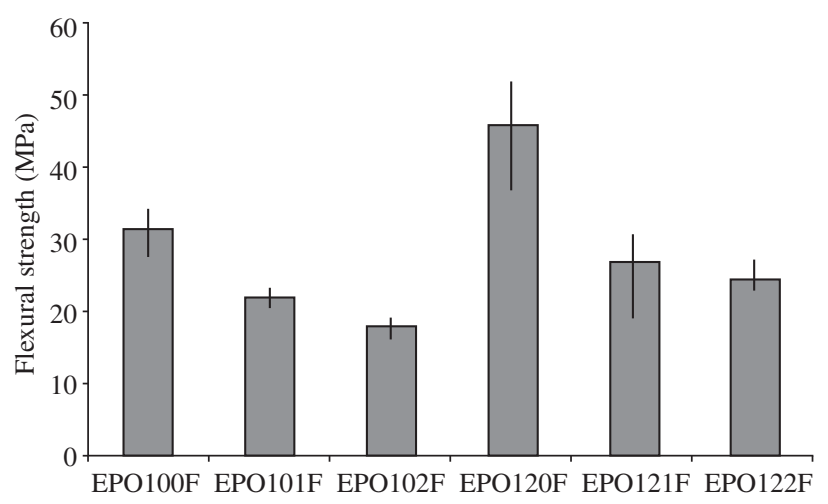

Figure 6. Compressive strength comparison of all polymer concrete formulations.

signs of brittleness behavior of unreinforced polymer concrete. The use of those fibers, in specific applications, may solve two problems, namely, elimination of an environmental pollutant and provision of an alternative material for the construction industry.

\section{Acknowledgements}

The financial support of FAPERJ under the JOVEM CIENTISTA DO ESTADO program are gratefully acknowledged and the Head of Materials Engineering Department of IPRJ/UERJ.

\section{References}

1. Rowell RM, Han JS, Rowell JS. Characterization and factors effecting fiber properties. In Natural Polymers and Agrofibers Based Composites. Frollini E, Leão AL, Mattoso LHC. (Eds.). São Carlos: Embrapa Intrumentação Agropecuéria; 2000.

2. Filho DCM, Santos AMM. Cadeia têxtil: estrutura e estratégias no comércio exterior. BNDES Setorial. 2002; 15:113-136.
3. Reis JML, Ferreira AJM. Fracture behavior of glass fiber reinforced polymer concrete. Polymer Testing. 2003; 22(2):149-153.

4. Reis JML, Ferreira AJM. Assessment of fracture properties of epoxy polymer concrete reinforced with short carbon and glass fibers. Construction and Building Materials. 2004; 18(7):523-528.

5. Reis JML. Fracture and flexural characterization of natural fiber reinforced polymer concrete. Construction and Building Materials. 2006; 20(9):673-678.

6. Aspiras FF, Manalo JRI. Utilization of textile waste cuttings as building material. Journal of Materials Processing Technology. 1995; 48(1-4):379-384.

7. Fowler DW. Polymers in concrete: a vision for the $21^{\text {st }}$ century. Cement and Concrete Composites. 1999; 21(5-6):449-452.

8. Czarnecki L. Polymer is concrete on the edge of the millennium. In Proceedings of the $10^{\text {th }}$ International Conference on Polymers in Concrete; 2001 May; Hawaii. USA. Hawaii: [s.n.]; 2001. Paper 93.

9. Letsh R. Polymer Concrete properties and structural applications. In Proceedings of International Conference on Polymer Concrete. Mortars and Asphalts; 2002; Oporto, Portugal. Oporto: [s.n.]; 2002. p. 31-43.

10. CPT PC-2: Method of making polymer concrete and mortar specimens. TC 113. London: RILEM; 1995.

11. CPT PC-8: Method of test for flexural strength and deflection of polymermodified mortar. TC 113. London: RILEM; 1995.

12. ASTM C 348-02: Standard Test Method for flexural strength and modulus of hydraulic cement mortars. [S.L.]: ASTM; 2002.

13. ASTM C39 / C39M - 05e1: Standard Test Method for Compressive Strength of Cylindrical Concrete Specimens. [S.L.]: ASTM; 2005.

14. Rebeiz KS, Shearl SP. Fowler DW: recommended design procedure in shear for steel-reinforced polymer concrete. ACI Structural Journal. 1993 90(5):562-567

15. Ribeiro MCS, Tavares CML, Figueiredo M, Ferreira AJM, Fernandes AA. Bending Characteristics of Resin Concretes. Materials Research. 2003; 6(2):247-254.

16. Wang Y, Zureick AH, Cho B, Scott DE. Properties of fibre reinforced concrete using recycled fibres from carpet industrial waste. Journal of Materials Science. 1994; 29(16):4191-4199. 